\title{
Are Standard Doses of Renally-Excreted Antiretrovirals in Older Patients Appropriate: A PBPK Study Comparing Exposures in the Elderly Population With Those in Renal Impairment
}

\author{
M. De Sousa Mendes ${ }^{1}$ (D) Manoranjenni Chetty $^{1}$ (D)
}

Published online: 10 October 2019

(c) The Author(s) 2019

\begin{abstract}
Background and Objectives The elderly population receives the majority of prescription drugs but are usually excluded from Phase 1 clinical trials. Alternative approaches to estimate increases in toxicity risk or decreases in efficacy are therefore needed. This study predicted the pharmacokinetics (PK) of three renally excreted antiretroviral drugs in the elderly population and compared them with known exposures in renal impairment, to evaluate the need for dosing adjustments.

Methods The performance of the physiologically based pharmacokinetic (PBPK) models for tenofovir, lamivudine and emtricitabine were verified using clinical data in young and older subjects. Models were then used to predict PK profiles in a virtual population aged 20 to 49 years (young) and a geriatric population aged 65 to 74 years (elderly). Predicted exposure in the elderly was then compared with exposure reported for different degrees of renal impairment, where doses have been defined.

Results An increase in exposure (AUC) with advancing age was predicted for all drugs. The mean ratio of the increase in exposure were 1.40 for emtricitabine, 1.42 for lamivudine and 1.48 for tenofovir. The majority of virtual patients had exposures that did not require dosage adjustments. About $22 \%$ of patients on tenofovir showed exposures similar to that in moderate renal impairment, where dosage reduction may be required.

Conclusion Comparison of the exposure in the elderly with exposure observed in patients with different levels of renal impairment, indicated that a dosage adjustment may not be required in elderly patients on lamivudine, emtricitabine and the majority of the patients on tenofovir. Clinical trials to verify these predictions are essential.
\end{abstract}

\section{Key Points}

Higher concentrations than observed in young subjects are predicted for tenofovir, lamuvidine and emtricitabine after standard doses are given to elderly subjects.

Based on exposures reported for renal impairment, the majority of elderly virtual patients did not require dosage adjustments, with the exception of about $20 \%$ of patients on tenofovir, where exposure could be compared with moderate renal impairment.

Clinical studies to verify the predicted exposures, especially with tenofovir, are warranted.

Manoranjenni Chetty

manoranjenni.chetty@certara.com

1 Certara UK, Simcyp Division, Sheffield, UK

\section{Introduction}

Advancing age is accompanied by numerous physiological, biochemical and anatomical changes that are likely to affect the pharmacokinetics (PK) and pharmacodynamics (PD) of drugs. It is therefore not surprising that elderly patients are most susceptible to adverse drug reactions [1]. Although various changes that could potentially impact the absorption, distribution, metabolism and excretion of drugs in the older patient are reported, prospective studies evaluating the relevance of prescribed drug doses in this vulnerable population group are uncommon. Drug dosing regimens that are designed for pharmacotherapy in younger adults are used in the elderly patient, without always verifying whether they are appropriate or not. In the absence of adequate clinical trials in this special population, physiologically-based pharmacokinetic (PBPK) modelling can be used to predict the possible impact of changes associated with aging on the pharmacokinetics of specific drugs. The physiological, 
anatomical and biological changes in the elderly that are of relevance during PBPK modelling have recently been reviewed [2-4]. Some of the key changes described in these reviews include a trend towards a decrease in height and weight in the older patient, possible changes in gastric emptying time and intestinal transit time, a reduction in the size of some organs (including the liver), a reduction in cardiac output with a consequent reduction in blood flow to organs such as the liver and kidneys, possible changes in drug metabolising enzymes and a decline in renal function.

Significant evidence exists for the age-related decline in renal function [5-7]. Both plasma creatinine and glomerular filtration rates are reduced in older subjects. Despite our knowledge of diminishing renal function with advancing age, information on the impact of aging on the PK of drugs, such as some antiretrovirals that are mainly excreted unchanged by the kidney, is sparse. Tenofovir (TDF), lamivudine (3TC) and emtricitabine (FTC) are examples of antiretrovirals that are excreted predominantly unchanged by the kidney. Prescribing information for these three drugs indicate that dosage adjustments corresponding to different levels of renal impairment are required. Despite these recommendations [8-10], the PK of these three drugs in the geriatric population have not been investigated to determine whether dosage adjustments are appropriate or not. Labelling recommendations for dosing in the elderly population for all three drugs state that "Clinical trials did not include sufficient numbers of subjects aged 65 and over to determine whether they respond differently from younger subjects". Studies to guide informed dosing in this population are therefore required.

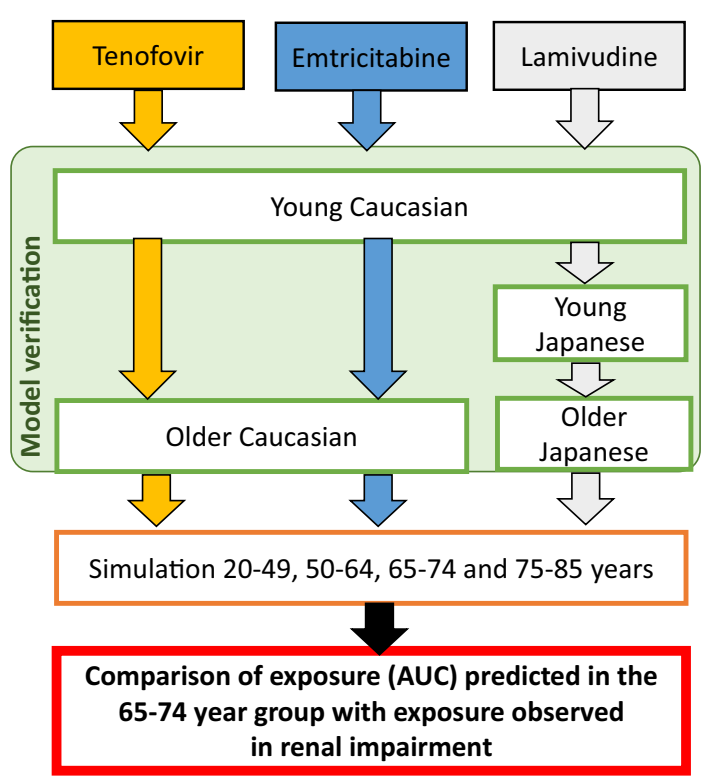

Fig. 1 Diagram illustrating the workflow for the study
The objective of this study was to use PBPK modelling to predict changes in the exposure to TDF, FTC and 3TC in older patients and to evaluate whether the changes may warrant dosage adjustments in this patient group, based on dosing adjustments recommended for individuals with different degrees of renal impairment.

\section{Methods}

The workflow of the present study is shown in Fig. 1, illustrating the use of the best practice approach for model verification and application. Briefly, following verification of the drug models in younger and older populations using observed data, the models were used to predict the PK in different age groups using 1000 individuals in each group, to capture population variability. The predicted exposure (as assessed by area under the plasma concentration versus time curve [AUC]) in the 65-74 year group (referred to in this study as the 'elderly' age group) was then compared with the reported exposure in patients with different levels of renal impairment. Since dosage recommendations have been made for patients with different levels of renal impairment, comparisons of the drug exposures in these patients were used to determine whether dosage adjustments should be considered in the elderly patient.

The Simcyp population-based simulator (V17R1) was used for all the PBPK modelling and simulations. For model performance verification, concentration-time data were extracted from publications using the GetData Graph Digitizer (version 2.22, http://www.getdata-graph-digitizer.com).

\subsection{Population Models}

The Sim-Geriatric population model, which is available in the Simcyp simulator, was used to simulate the elderly population and has been described and verified previously [2] This model includes subjects that are 65 years and older and accounts for the age-related changes such as demographics, cardiac output, liver weight, liver blood flow and reduction in glomerular filtration rate (GFR). The age-related changes in GFR are calculated using age-related plasma creatinine concentrations derived from the NHANES database [11] and based on the Cockcroft-Gault equation. The simulated GFR obtained was verified against observed literature data $[2,5-7,12]$ and presented previously [2]. A reduction in blood flow to the kidney, reflective of the reduced cardiac output with age, is also included in the model. There is a paucity of literature information on kidney transporter abundances or activity in the older subjects and hence no changes could be included in the Sim-Geriatrics population. The three drugs studied here are mainly renally excreted and are poorly bound to plasma protein; therefore, the key 
Table 1 Summary of drug dependent parameters

\begin{tabular}{llll}
\hline & Tenofovir & Lamivudine & Emtricitabine \\
\hline PBPK model & Full & Full & Full \\
MW $(\mathrm{g} / \mathrm{mol})$ & $287[34]$ & $229[25]$ & $247[10]$ \\
$\mathrm{pKa}$ & $3.7-6.5[34]$ & $4.5[25]$ & $2.65[10]$ \\
$\log \mathrm{P}$ & $-2.21[64]$ & $-0.7[9]$ & $-0.43[10]$ \\
$\mathrm{fu}$ & $0.993[8]$ & $0.84^{\mathrm{a}}$ & $0.96[10]$ \\
Main binding protein & Albumin & Albumin & Albumin \\
B/P ratio & $0.58[65]$ & $1.3[66]$ & $1[10]$ \\
fa & $0.32[18]$ & $0.89[9]$ & $1[10]$ \\
ka $\left(\mathrm{h}^{-1}\right)$ & $1[18]$ & $1.04[24]$ & $0.54[30]$ \\
Simcyp predicted Vss & $4.87^{\mathrm{b}, \mathrm{c}}$ & $0.49^{\mathrm{b}}$ & $0.51^{\mathrm{b}}$ \\
$\quad(\mathrm{L} / \mathrm{kg})$ & & & \\
Total CL $(\mathrm{L} / \mathrm{h})$ & $16.2[17]$ & $23.9[25]$ & $18[31]$ \\
$\mathrm{CL}_{\mathrm{R}}(\mathrm{L} / \mathrm{h})$ & $13.12[17]$ & $16.8[25]$ & $13[10,31]$ \\
$\mathrm{CL}_{\mathrm{ad}}(\mathrm{L} / \mathrm{h})$ & $3.1[17]$ & $7.1[25]$ & $5[31]$ \\
\hline
\end{tabular}

$B / P$ ratio blood to plasma ratio, $C L$ clearance, $C L_{a d}$ additional systemic clearance, $C L_{R}$ renal clearance, $f u$ free fraction, $k a$ first order absorption rate, $M W$ molecular weight, $P B P K$ physiologically-based pharmacokinetic, $p K a$ is the negative log of the acid dissociation constant, $\log P$ is the partition coefficient of the molecule between aqueous and lipophillic phases, $f a$ is the fraction of the drug absorbed, Vss is the steady state volume of distribution

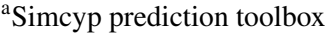

${ }^{\mathrm{b}}$ Predicted using method 2

${ }^{c}$ Predicted using method 2, scaling factor of 17.88 optimised [20]

parameter that will impact the PK is the GFR. Since the available clinical data on the PK of TDF, FTC and 3TC were obtained in clinical trials on Caucasian and Japanese subjects, the Sim-NEurCaucasian and Sim-Japanese populations [13] were used for verification of the drug PBPK models.

\subsection{Drug Models and Performance Verification}

The PBPK models for TDF, FTC and 3TC in the elderly population were based on previously developed models in a Caucasian population [14]. Input parameters for the PBPK drug models used in this study are summarised in Table 1.

The performance of the PBPK models was verified by visual inspection of the simulated and clinically observed concentration-time profiles as well as comparison of the predicted and observed PK parameters. Simulated concentration-time profiles were acceptable when the observed concentrations were within the 5th to 95th percentiles of the simulated concentrations. Additionally, the predicted: observed ratios of the PK parameters had to be within twofold of the observed data [15].

\subsubsection{Tenofovir Physiologically-Based Pharmacokinetic (PBPK) Model}

Tenofovir is administered as a rapidly hydrolysed prodrug, tenofovir disoproxil fumarate (TDF). The $300 \mathrm{mg}$ TDF dose is equivalent to $136 \mathrm{mg}$ of tenofovir base $[16,17]$. TDF absorption was described using a first-order absorption model [18]. The distribution model of TDF was updated relative to the previous model [14], where a full PBPK model was used to describe the distribution of the drug. The volume of distribution was predicted using the Rodgers and Roland method [19]. A Kp scaling factor (tissue to plasma partition coefficient) of 17.88 was estimated by fitting the observed PK profile from Mathias et al. 2007 [20] in order to recover the maximum concentration $\left(C_{\max }\right)$ of the drug. The renal clearance of TDF represented $75 \%$ of the total clearance and was $13.12 \mathrm{~L} / \mathrm{h}$ in healthy volunteers [17].

This model was first verified in the Caucasian population using available clinical data obtained after multiple administrations of TDF $300 \mathrm{mg}$ (equivalent to $136 \mathrm{mg}$ of tenofovir, which was used in the simulations) [21, 22]. Ten trials of 10 subjects aged between 20 and 50 years, with $50 \%$ being female in each trial, were simulated using the SIM-NEurCaucasian population. Predicted $C_{\max }, \mathrm{AUC}_{\infty}$ and PK profiles were compared with the observed data [21, 22].

The performance of the model in predicting clearance in the older population was verified by comparing predicted PK profiles with observed median PK profiles obtained after multiple administration of TDF $300 \mathrm{mg}$ [23]. Ten trials of 12 subjects aged between 53 and 66 years with $50 \%$ being female in each trial were simulated according to the design in the clinical trial from Dumond et al. [23].

\subsubsection{Lamivudine PBPK Model}

The absorption of 3TC was described by a first-order absorption model [24]. A full PBPK model was used, with the volume of distribution predicted using the Rodgers and Roland method [19]. Renal clearance of 3TC represented $70 \%$ of the total clearance and was $16.8 \mathrm{~L} / \mathrm{h}$ in healthy volunteers [25].

The model was initially verified against clinical PK profiles obtained in a young Caucasian population aged between 29 and 41 years [26] as well as a group aged between 18 and 54 years [27]. Because the only study that reported the PK of 3TC in the elderly population was conducted in a Japanese population [28], the 3TC model was first verified in young Japanese subjects. PK profiles were obtained after simulation of 10 trials of six subjects each, aged between 22 and 44 years, with $16.7 \%$ being female. These virtual subjects received lamivudine $150 \mathrm{mg}$ twice a day and predicted PK profiles were compared with observed data from Tatsunami et al. [29]. The model was further verified by comparing simulations of 10 trials of six male subjects aged between 
20 and 21 years, who were administered a single 100-mg dose of 3TC, with observed data from Shibata et al. [28]. After verification of the $3 \mathrm{TC}$ model in young Japanese subjects, the model was further verified by simulating 10 trials of six male subjects aged between 65 and 70 years in the SIM-Japanese population according to the Shibata et al. [28] study design.

\subsubsection{Emtricitabine PBPK Model}

A first-order absorption model [30] with a full PBPK distribution model was used for FTC. The renal clearance of FTC represented $70 \%$ of the total clearance and was $16.8 \mathrm{~L} / \mathrm{h}$ in healthy volunteers [31]. The model was first verified in the Caucasian population using available clinical data obtained after multiple administration of FTC $200 \mathrm{mg}[32,33]$. Ten trials of 10 subjects aged between 20 and 50 years, with $50 \%$ being female in each trial, were simulated in the Caucasian population. The predicted $C_{\max }, \mathrm{AUC}_{\infty}$ and $\mathrm{PK}$ profiles obtained were compared with the observed data [32,33].

To verify the model in the older population, 10 trials of 12 subjects aged between 53 and 66 years, with $50 \%$ being female, receiving multiple doses of FTC $200 \mathrm{mg}$, were simulated according to the trial design of Dumond et al. [23], using the Simcyp NEurCaucasian population.

\subsection{Model Application}

Following appropriate verification of the three PBPK models in the Caucasian and Japanese populations, the PK of the three drugs were simulated in different age groups and compared. The models were used to predict PK profiles for TDF $300 \mathrm{mg}$, 3TC $300 \mathrm{mg}$ and FTC $200 \mathrm{mg}$, in Caucasian subjects aged 20-49 years; 50-64 years, 65-75 years and 76-85 years. One hundred trials with 10 individuals were simulated using the Sim-Geriatric population for the 65-74 years and 75-85 years age groups. Since drug response has been associated with the AUC for these drugs $[26,28]$, differences in exposure $\left(\mathrm{AUC}_{\infty}\right)$ were compared between the age groups to determine whether any changes or trends could be observed with advancing age. In the text that follows, the group aged $65-74$ years is referred to as the elderly population. The group aged $>75$ years was not analysed extensively since the lifespan of HIV/AIDS patients seldom exceed 75 years.

The predicted mean $\mathrm{AUC}_{\infty}, C_{\min }$ (concentration before the next dose) and $C_{\max }$ from subjects aged 20-49 years (young subjects) were compared with the PK parameters from subjects aged 65-74 years (elderly subjects) for the three drugs, after multiple drug administration (TDF: $300 \mathrm{mg}$ once daily [qd], 3TC: $150 \mathrm{mg}$ twice daily [bid], FTC: $200 \mathrm{mg} \mathrm{qd}$ ).

\subsection{Comparison of Predicted Exposure $\left(A U C_{0-\infty}\right)$ in Elderly Subjects with $A U C_{0-\infty}$ Published for Different Degrees of Renal Impairment}

Recommended dosage adjustments in renal impairment, based on differences in exposure associated with different degrees of renal dysfunction, are available in the prescribing information for each of the three drugs. In this study, predicted exposure changes for each of the three drugs in the elderly were compared with the published changes resulting from different levels of renal dysfunction, to determine whether dosage adjustments are required in elderly patients taking standard doses of 3TC, FTC or TDF. Predicted exposure in the elderly was found to be similar to the observed exposure in a specific category of renal impairment when the ratio of the mean predicted AUC: observed AUC in the relevant category of renal impairment were within the bioequivalence limits $(\geq 0.8$ and $\leq 1.25)$ [15].

Table 2 Observed versus predicted $\mathrm{AUC}_{\infty}$ and $C_{\max }$ in young population (aged 20-50 years)

\begin{tabular}{|c|c|c|c|c|c|c|}
\hline & \multicolumn{3}{|l|}{$\mathrm{AUC}_{\infty}(\mathrm{mg} / \mathrm{h} / \mathrm{L})$} & \multicolumn{3}{|l|}{$C_{\max }(\mathrm{mg} / \mathrm{L})$} \\
\hline & Observed & Predicted & Pred/obs & Observed & Predicted & Pred/obs \\
\hline \multirow[t]{2}{*}{ Tenofovir } & $2.84(0.68)^{\mathrm{a}}[21]$ & $2.41(1.78-3)^{\mathrm{b}}$ & 0.85 & $0.279(0.06)^{\mathrm{a}}[21]$ & $0.267(0.20-0.33)^{\mathrm{b}}$ & 0.96 \\
\hline & $1.74(1.48-2.03)^{\mathrm{c}}[22]$ & $2.08(1.59-2.52)^{\mathrm{d}}$ & 1.20 & $0.263(0.223-0.311)^{\mathrm{c}}[22]$ & $0.224(0.17-0.29)^{\mathrm{d}}$ & 0.85 \\
\hline \multirow[t]{2}{*}{ Lamivudine } & $10.89(8.33-14.24)^{\mathrm{c}}[26]$ & $9.60(8.56-10.77)^{\mathrm{d}}$ & 0.88 & $2.52(2.14-2.97)^{\mathrm{c}}[26]$ & $2.71(2.2-3.24)^{\mathrm{d}}$ & 1.08 \\
\hline & $8.70(8.28-9.14)^{\mathrm{c}}[27]$ & & 1.1 & $1.97(1.84-2.11)^{\mathrm{c}}[27]$ & & 1.37 \\
\hline \multirow[t]{2}{*}{ Emtricitabine } & $9.99(3.1)^{\mathrm{a}}[32]$ & $10.05(9.19-10.86)^{\mathrm{b}}$ & 1 & $1.85(0.66)^{\mathrm{a}}[32]$ & $1.84(1.52-2.2)^{\mathrm{b}}$ & 0.99 \\
\hline & $11.2^{\mathrm{c}}[33]$ & $13.24(12.69-13.88)^{\mathrm{d}}$ & 1.18 & $2.28^{\mathrm{c}}[33]$ & $1.94(1.67-2.28)^{\mathrm{d}}$ & 0.85 \\
\hline
\end{tabular}

$A U C$ area under the plasma concentration-time curve, $C_{\max }$ maximum concentration, $S D$ standard deviation

${ }^{\mathrm{a}}$ Mean (SD)

${ }^{b}$ Mean (mean range)

${ }^{\mathrm{c}}$ Geometric mean (confidence interval)

${ }^{\mathrm{d}}$ Geometric mean (geometric mean range) 

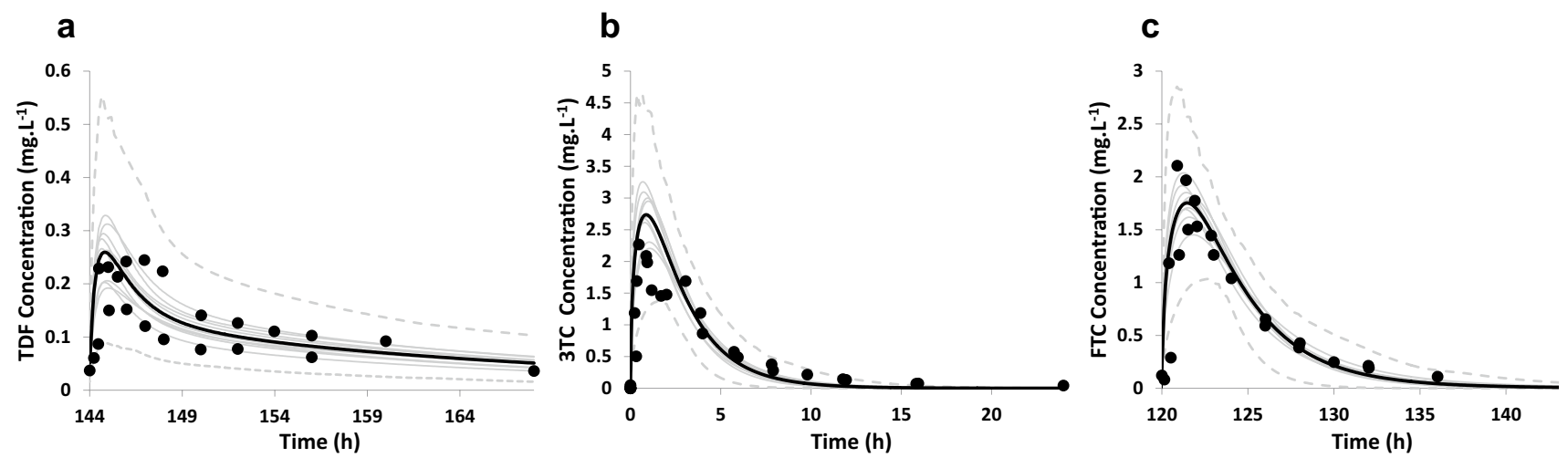

Fig. 2 Model performance verification with clinical studies in young subjects. Simulated (black line) and observed (data points [21, 22, $26,27,32,33])$ mean plasma concentration-time profile after multiple administration of TDF $300 \mathrm{mg}$ (a), single administration of 3TC $300 \mathrm{mg}$ (b) and multiple administration of FTC $200 \mathrm{mg}$ (c) in the

young population. The grey lines represent the predictions from individual trials (10 trials $\times 10$ subjects; $20-50$ years). Dotted lines represent the 5th and 95th percentile of the total virtual population. 3TC lamivudine, FTC emtricitabine, $T D F$ tenofovir

Table 3 Observed versus predicted mean lamivudine $\mathrm{AUC}_{\infty}$ and $\mathrm{C}_{\max }$ in young (aged 22-44 years) Japanese population

\begin{tabular}{|c|c|c|c|c|c|c|}
\hline \multirow[t]{2}{*}{ Dosage regimen } & \multicolumn{3}{|l|}{$\mathrm{AUC}_{\infty}(\mathrm{mg} / \mathrm{h} / \mathrm{L})$} & \multicolumn{3}{|l|}{$C_{\max }(\mathrm{mg} / \mathrm{L})$} \\
\hline & Observed & Predicted & Pred/obs & Observed & Predicted & Pred/obs \\
\hline Multiple dose of $150 \mathrm{mg}$ bid & $6.78( \pm 2.76)^{\mathrm{a}}[29]$ & $5.29(4.4-6.31)^{\mathrm{b}}$ & 0.78 & $1.44( \pm 0.26)^{\mathrm{a}}[29]$ & $1.53(1.14-1.82)^{\mathrm{b}}$ & 1.06 \\
\hline Single dose of $100 \mathrm{mg}$ & $5.0( \pm 1.1)^{\mathrm{a}}[28]$ & $3.3(2.75-3.75)^{\mathrm{b}}$ & 0.66 & $1.46( \pm 0.68)^{\mathrm{a}}[28]$ & $0.96(0.73-1.16)^{\mathrm{b}}$ & 0.66 \\
\hline
\end{tabular}

$A U C$ area under the plasma concentration-time curve, bid twice daily, $C_{\max }$ maximum concentration, $S D$ standard deviation

${ }^{\mathrm{a}}$ Mean (SD)

${ }^{\mathrm{b}}$ Mean (range)

Table 4 Observed versus predicted $\mathrm{AUC}_{\infty}$ and $C_{\max }$ in the older population (TDF and FTC: 53-66 years; 3TC: 65-70 years)

\begin{tabular}{|c|c|c|c|c|c|c|}
\hline \multirow[t]{2}{*}{ Drug } & \multicolumn{3}{|l|}{$\mathrm{AUC}_{\infty}(\mathrm{mg} / \mathrm{h} / \mathrm{L})$} & \multicolumn{3}{|l|}{$C_{\max }(\mathrm{mg} / \mathrm{L})$} \\
\hline & Observed & Predicted & Pred/obs & Observed & Predicted & Pred/obs \\
\hline Tenofovir & $3.38^{\mathrm{c}}[23]$ & $2.77(2.12-3.52)^{\mathrm{d}}$ & 0.82 & $0.307^{\mathrm{c}}[23]$ & $0.27(0.20-0.36)^{\mathrm{d}}$ & 0.88 \\
\hline Emtricitabine & $12.3^{\mathrm{c}}[23]$ & $13.3(12.5-13.6)^{\mathrm{d}}$ & 1.08 & $1.81^{\mathrm{c}}[23]$ & $2.03(1.77-2.41)^{\mathrm{d}}$ & 1.12 \\
\hline Lamivudine & $6.8( \pm 1.05)^{\mathrm{a}}[28]$ & $4.3(3.54-5.54)^{\mathrm{b}}$ & 0.63 & $1.67( \pm 0.73)^{\mathrm{a}}[28]$ & $1.1(0.8-1.4)^{\mathrm{b}}$ & 0.66 \\
\hline
\end{tabular}

$A U C$ area under the plasma concentration-time curve, $C I$ confidence interval, $C_{\max }$ maximum concentration, $S D$ standard deviation

${ }^{\mathrm{a}}$ Mean (SD)

${ }^{\mathrm{b}}$ Mean (mean range)

${ }^{\mathrm{c}}$ Geometric mean (CI)

${ }^{\mathrm{d}}$ Geometric mean (geometric mean range)

\section{Results}

Predicted PK parameters obtained from model verification simulations are summarised in Table 2 and the predicted and observed concentration profiles are presented in Fig. 2. Visual inspection of the concentration-time profiles indicate acceptable recovery of the clinical data since the majority $(99.8 \%)$ of the observed concentrations fall within the 5th-95th percentiles of the predicted profiles. Similarly, it can be seen from Table 2 that the models recover the clinical data acceptably since the predicted: observed ratios of the PK parameters are within twofold of the observed data [15].

The simulated and observed [28, 29] 3TC PK profiles and parameters in the young Japanese population are presented in Table 3. The $\mathrm{AUC}_{\infty}$ in the Japanese population observed by Shibata et al. [28] appeared to be marginally 

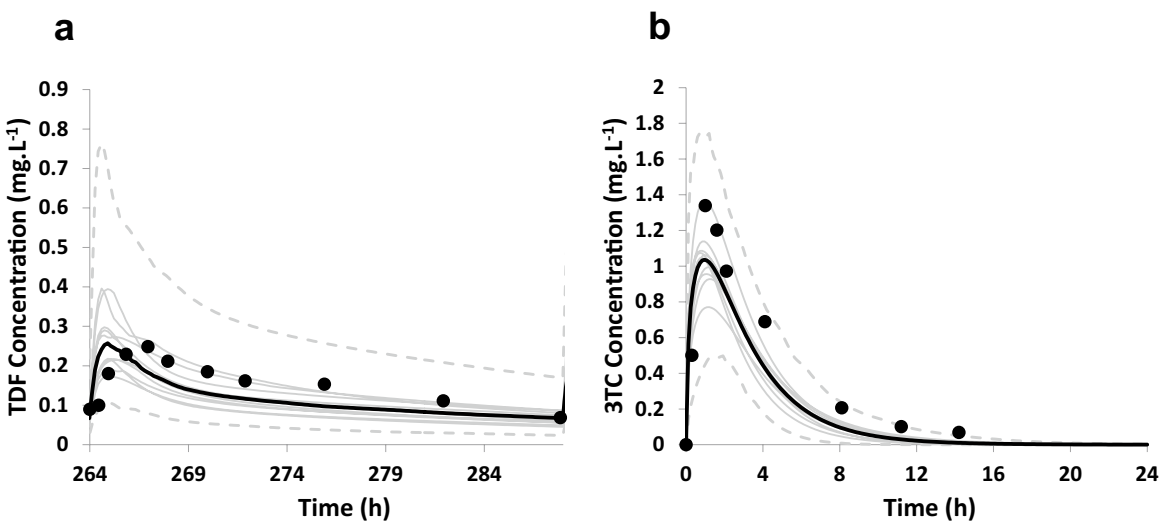

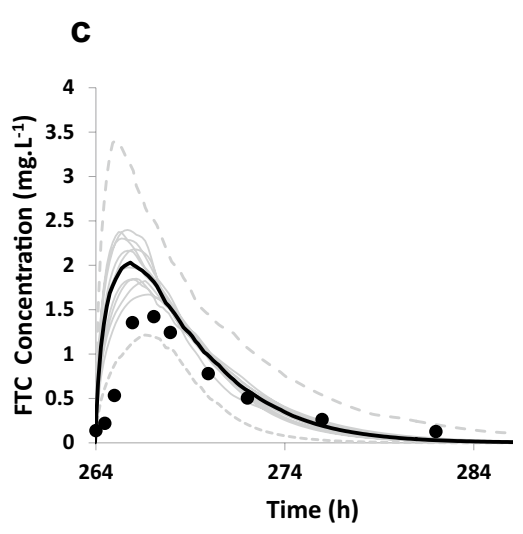

Fig. 3 Model performance verification using clinical studies in older subjects. Concentration-time profiles in the older population. a Simulated (mean - black line) and observed (data points [23]) plasma concentration-time profile after multiple administrations of TDF $300 \mathrm{mg}$ (10 trials $\times 12$ Caucasian subjects, aged 53-66 years). b Simulated (mean-black line) and observed (data points [23]) plasma concentration-time profile after a single administration of 3TC $200 \mathrm{mg}$ (10 trials $\times 6$ Japanese subjects, aged $65-70$ years). c Simulated (meanblack line) and observed (data points [23]) plasma concentrationtime profile after multiple administrations of FTC $200 \mathrm{mg}$ (10 trials $\times 12$ Caucasian subjects, aged 53-66 years). In all the figures, the grey lines represent mean predictions from individual trials and the dotted lines represent the 5th and 95th percentiles for the predicted data. 3TC lamivudine, FTC emtricitabine, TDF tenofovir

\section{Tenofovir}

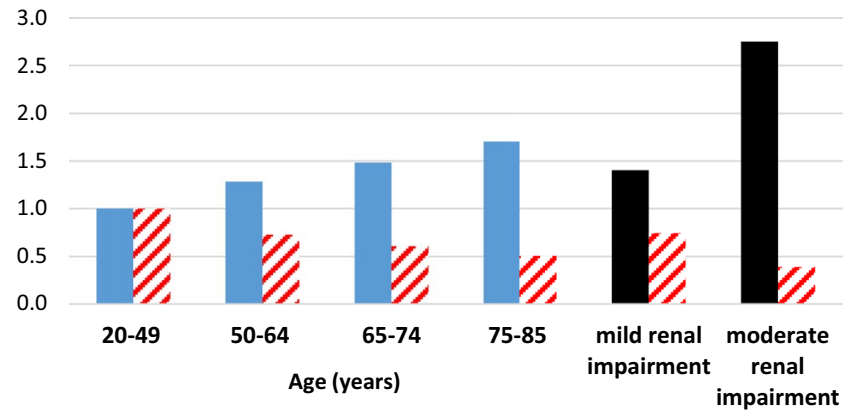

\section{Lamivudine}

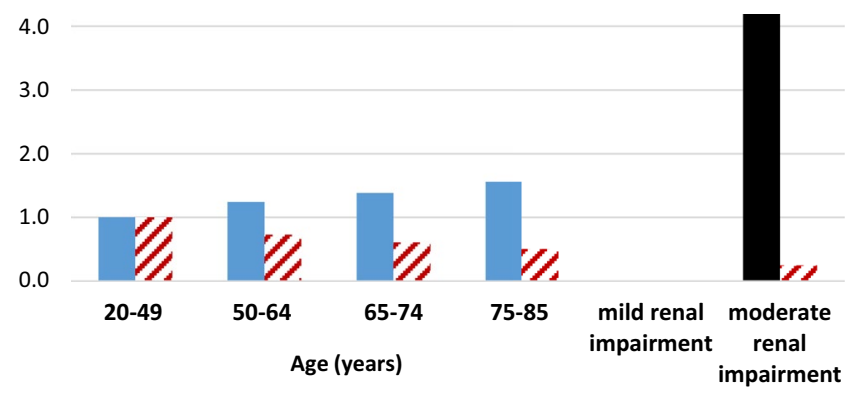

Fig. 4 Comparative changes in exposure (blue bars) and glomerular filtration rate (GFR - patterned red bars) with age and in renal impairment. Both the predicted area under the plasma concentration-time curve $\left(\mathrm{AUC}_{\infty}\right)$ and $\mathrm{GFR}$ for each age group are presented

underestimated (predicted/observed ratios of 0.66 but within the twofold range of acceptance) for the young and elderly population; however, the model is able to recover the clinical

\section{Emtricitabine}

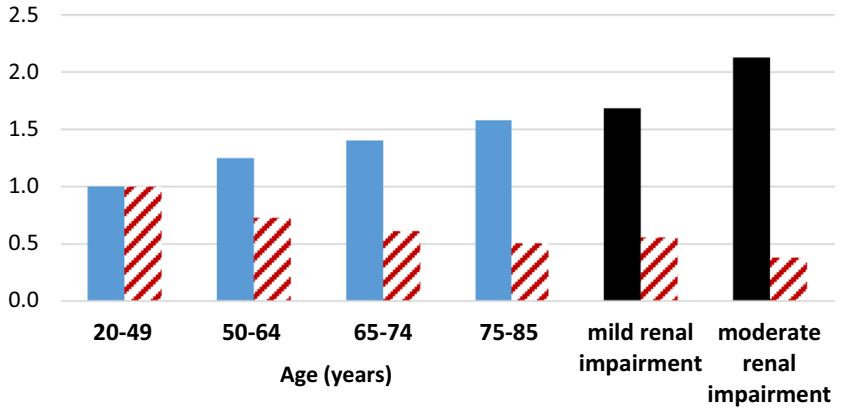

as ratios relative to the values in the young population. The observed changes in AUC and GFR reported for different levels of renal impairment are illustrated as black and red patterned bars, respectively

data on the age effect (Tables 3,4). An $\mathrm{AUC}_{\infty}$ increase of $30 \%$ is predicted in the elderly and the observed $\mathrm{AUC}_{\infty}$ increase is $37 \%$ [28], indicating acceptability of the model. 


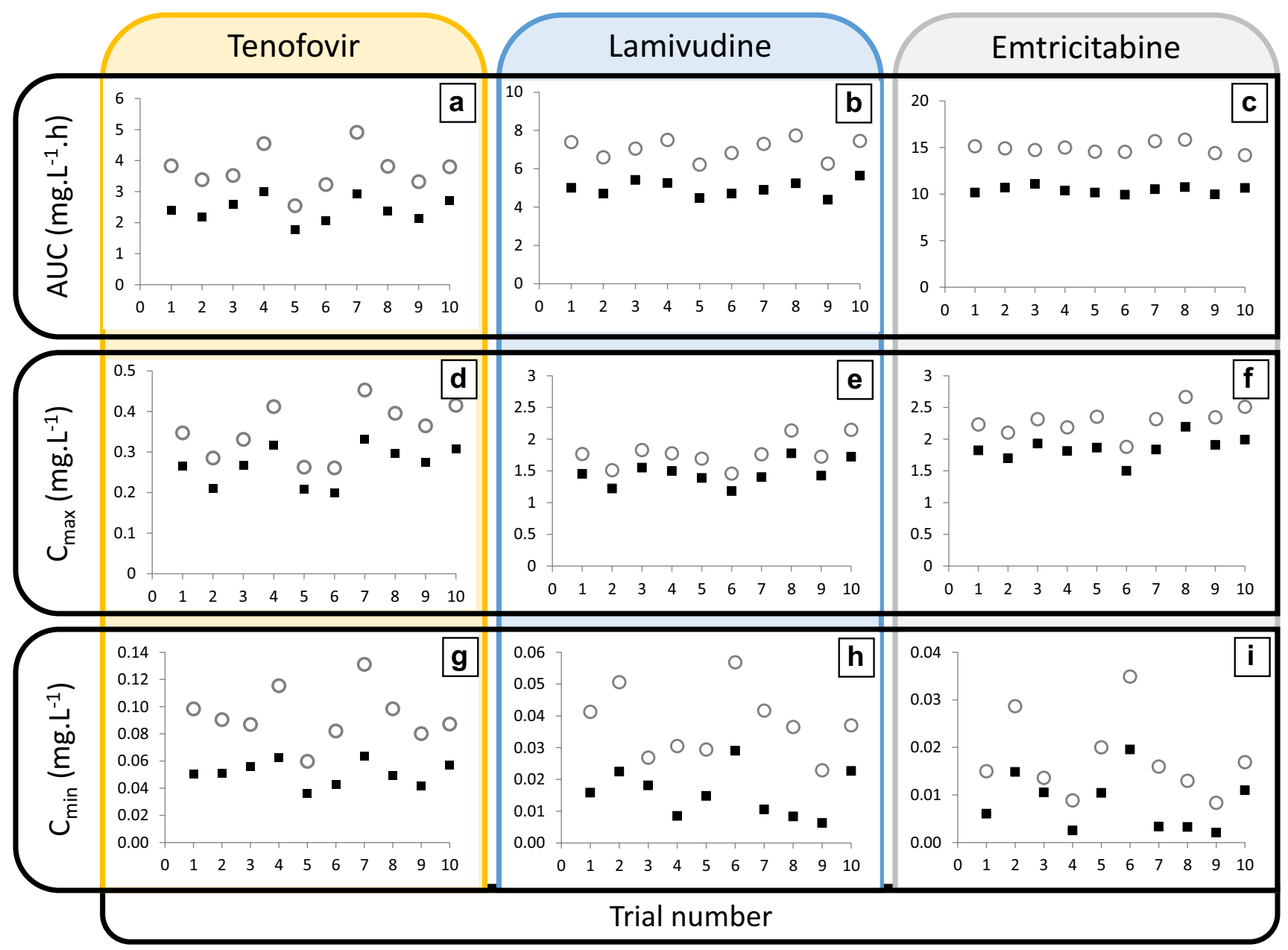

Fig. 5 Mean predicted changes in drug exposure with age. $\mathrm{AUC}_{\infty}$ $(\mathbf{a}-\mathbf{c}), C_{\max }(\mathbf{d}-\mathbf{f})$ and $C_{\min }(\mathbf{g}-\mathbf{i})$ after multiple administration of tenofovir disoproxil fumarate $300 \mathrm{mg} \mathrm{qd}(\mathbf{a}, \mathbf{d}, \mathbf{g})$, lamivudine $150 \mathrm{mg}$ bid (B,E,H) and emtricitabine $200 \mathrm{mg}$ qd (c, f, i) in elderly (aged 65-74 years; open circle) and young (aged 25-50 years; black square)

Simulated and observed [23, 28] PK profiles and PK parameters of the three antiretrovirals in the older population (TDF and FTC: 53-66 years; 3TC: 65-70 years) are shown in Fig. 3 and Table 4.

A decrease in systemic clearance with a corresponding increase in $\mathrm{AUC}_{\infty}$ (Fig. 4) was predicted with an increase in age with all three drugs. Predicted mean $\mathrm{AUC}_{\infty}$ of $3 \mathrm{TC}$ in the elderly population (65-74 years) was $42 \%$ higher (mean $14.1 \mathrm{mg} / \mathrm{L} / \mathrm{h}$; coefficient of variation $[\mathrm{CV}] 28 \%$ ) than in the young subjects (20-49 years) (mean $9.89 \mathrm{mg} / \mathrm{L} / \mathrm{h} ; \mathrm{CV} 26 \%$ ). Predicted mean AUC increases for TDF and FTC were $48 \%$ and $40 \%$, respectively, for the same age groups. Figure 5 illustrates that higher exposure $\left(\mathrm{AUC}_{\infty}, C_{\max }\right.$ and $\left.C_{\min }\right)$ was predicted in the elderly population for all three drugs.

Predicted mean TDF $\mathrm{AUC}_{\infty}$ in the young population was $2.61(1.69-4.26) \mathrm{mg} / \mathrm{L} / \mathrm{h}$, which compared favourably with the mean $\mathrm{AUC}_{\infty}$ of $2.18 \mathrm{mg} / \mathrm{L} / \mathrm{h}(\mathrm{CV} 11.8 \%)$ observed
Caucasian populations. The trial number appears on the $x$-axis for each figure. Each data point represents the predicted mean parameter in each of the 10 trials. $A U C$ area under the plasma concentrationtime curve, bid twice daily, $C_{\max }$ maximum concentration, $C_{\min }$ concentration before the next dose, $q d$ once daily

in subjects with normal kidney function (predicted AUC/ observed $\mathrm{AUC}=1.21$ ) [34]. Observed exposure in mild renal impairment (creatinine clearance $\left[\mathrm{CL}_{\mathrm{CR}}\right] 50-80 \mathrm{~mL} /$ $\left.\mathrm{min}^{-1}\right)$ was $3.1 \mathrm{mg} / \mathrm{L} \mathrm{h}(\mathrm{CV} \%=30.3)$ while that in moderate renal impairment $\left(\mathrm{CL}_{\mathrm{CR}} 30-49 \mathrm{~mL} / \mathrm{min}\right)$ was $6.0(\mathrm{CV}$ 41.7\%) [34]. Predicted mean TDF $\mathrm{AUC}_{\infty}$ in elderly subjects was $3.87 \mathrm{mg} / \mathrm{L} / \mathrm{h}$ (CV 66\%; range for trials 2.45-6.4). This exposure is similar to the mean $\mathrm{AUC}_{\infty}$ of 3.1 (30.3\%) observed in subjects with mild renal dysfunction (predicted AUC/observed AUC $=1.24$ ). No dosage adjustment for TDF is recommended by the manufacturer for patients with mild renal dysfunction $\left(\mathrm{CL}_{\mathrm{CR}}>50 \mathrm{~mL} / \mathrm{min}\right)$ [8]. Based on this comparison of mean AUC values, no dosage adjustment is necessary in the elderly on a standard dose of TDF. However, when considering the 'extreme' end of the range, subjects with an $\mathrm{AUC}_{\infty}$ of $6.4 \mathrm{mg} / \mathrm{L} / \mathrm{h}$ are likely to be in the moderate renal impairment group (predicted AUC/observed 
AUC $=1.07)$. It is recommended that patients with moderate renal impairment receive a TDF dose of $300 \mathrm{mg}$ every 48 hours rather than daily [8]. Of the 1000 elderly subjects simulated, $22 \%$ had AUCs $>4.8 \mathrm{mg} / \mathrm{L} / \mathrm{h}$, suggesting that dosage adjustments will be required in those subjects.

Predicted mean FTC $\mathrm{AUC}_{\infty}$ in the young population was $10.64 \mathrm{mg} / \mathrm{L} / \mathrm{h}$ (range for trials 9.03-12.12), which compared favourably with the mean $\mathrm{AUC}_{\infty}$ of $11.8 \pm 2.9 \mathrm{mg} / \mathrm{L} / \mathrm{h}$ observed in subjects with normal kidney function (predicted AUC/observed AUC $=0.85$ ) [10]. Predicted mean FTC AUC $\infty$ in the elderly subjects increased to $14.94 \pm 2.6 \mathrm{mg} / \mathrm{L} / \mathrm{h}$ (range for trials 12.2-17.7). In a study on FTC PK in subjects with different levels of renal function, a mean AUC $\infty$ of $11.8 \pm 2.9 \mathrm{mg} / \mathrm{L} / \mathrm{h}$ was observed in subjects with a $\mathrm{CL}_{\mathrm{CR}}>80 \mathrm{~mL} / \mathrm{min}$. The predicted AUC/observed AUC in this group was 1.26 , indicating a possible match between the elderly and subjects with a $\mathrm{CL}_{\mathrm{CR}}>80 \mathrm{~mL} / \mathrm{min}$. A mean $\mathrm{AUC}_{\infty}$ of $19.9 \pm 1.2 \mathrm{mg} / \mathrm{L} / \mathrm{h}$ was observed in subjects with a $\mathrm{CL}_{\mathrm{CR}}$ between 50 and $80 \mathrm{~mL} / \mathrm{min}$ [10]. The predicted AUC/observed AUC in this group was 0.75. No change in dosage is recommended in patients with $\mathrm{CL}_{\mathrm{CR}} \geq 50 \mathrm{~mL} /$ min [10]. The predicted mean $\mathrm{AUC}_{\infty}$ for elderly subjects compares with the observed exposure in subjects having $\mathrm{CL}_{\mathrm{CR}} \geq 50 \mathrm{~mL} / \mathrm{min}$, indicating that no dosage adjustment is necessary in the elderly on a standard dose of FTC. When considering variability in the elderly population, there is unlikely to be a concern with subjects with a predicted AUC that is in the higher end of the predicted range of AUCs, since the predicted: observed ratio of 0.89 (i.e. 17.7/19.9) indicates that the exposures in these subjects are likely to correspond to those observed in subjects with a $\mathrm{CL}_{\mathrm{CR}}$ between 50 and $80 \mathrm{~mL} / \mathrm{min}$, where dosage adjustments are not recommended [10].

Predicted mean $3 \mathrm{TC} \mathrm{AUC}_{\infty}$ in the young population was $9.94 \mathrm{mg} / \mathrm{L} / \mathrm{h}$ (range for trials 7.84-12.21), which can be compared with the mean $\mathrm{AUC}_{\infty}$ of 11.25 (8.9-13.2) $\mathrm{mg} / \mathrm{L} / \mathrm{h}$ (predicted AUC/observed AUC $=0.88$ ) observed in subjects with normal kidney function [9]. Predicted geometric mean (95\% CI) $\mathrm{AUC}_{\infty}$ for $3 \mathrm{TC}$ in the elderly subjects was $13.8 \mathrm{mg} / \mathrm{L} / \mathrm{h}$ (range for trials 10.8-17.87). The observed geometric mean $(95 \% \mathrm{CI}) \mathrm{AUC}_{\infty}$ for $3 \mathrm{TC}$ was $10.89 \mathrm{mg} / \mathrm{L} / \mathrm{h}(8.33-14.24)$ in (predicted AUC/observed AUC $=1.26$ ) normal renal function and $45.66 \mathrm{mg} / \mathrm{L} / \mathrm{h}(32.86-63.43)$ in (predicted AUC/observed AUC $=0.30$ ) moderate renal impairment [9]. The predicted exposure in the elderly compares with the observed exposure in subjects having normal renal function [9]. Based on this comparison, no dosage adjustment may be required in the elderly on a standard dose of 3TC. The predicted range of AUCs in the elderly do not overlap with that observed for moderate renal impairment (predicted AUC/observed $\mathrm{AUC}=0.39$ for highest exposure), indicating that there is unlikely to be a concern with dosing, even in subjects with higher than an average increase in AUC.

\section{Discussion}

In this study, we adequately predicted the PK profiles of TDF, FTC and 3TC in young adults and older subjects using PBPK models. The verified models were then applied to predict the changes in key PK parameters with advancing age. There are only a few studies addressing the challenge of predicting the PK of drugs in the elderly populations using PBPK modelling $[4,35,36]$ and, to the best of our knowledge, none of them focussed on the PK profiles of these three antiretrovirals. Some population pharmacokinetic studies have attempted to determine whether age is a significant covariate in the PK of these drugs, but recommendations for dosing in the elderly population were not considered. The narrow age range and/or number of elderly patients in the clinical study as well as the integration of other agedependant covariates like $\mathrm{CL}_{\mathrm{CR}}$ were major limitations in these studies [37-40]. Considering the challenges with conducting prospective PK studies in the elderly, the results from our PBPK predictions provide an insight into differences in exposure that can be expected with standard doses of 3TC, TDF and FTC in the elderly patient (65-74 years), when compared with the young patient population in which dosage was established.

Our results indicate that a mean of $42 \%, 48 \%$ and $40 \%$ increase in exposure (AUC) is predicted for 3TC, TDF and FTC, respectively, in the elderly. Increasing plasma concentrations (Fig. 5) together with the higher drug exposure and decreasing GFR found with an increase in age (Fig. 4) are evident from the simulations. The clinical significance of the increase in exposure and the impact on dosing in the elderly was of interest in this study. A comparison of the predicted exposure (as assessed by $\mathrm{AUC}_{\infty}$ ) in the elderly with the observed exposure in patients with different levels of renal function indicated that no dosage adjustment is essential in the majority of elderly patients on standard doses of each of the three drugs. The predicted mean exposure of a standard dose of TDF in elderly subjects was similar to that reported in subjects with mild renal dysfunction and therefore indicated that no dosage adjustment is essential [8]. However, the greater variability in exposure predicted in the elderly suggests that some individuals may have exposures that approach that observed in moderate renal dysfunction. Our predictions suggested that about $22 \%$ of the virtual patients on TDF had exposures that could be compared with those in individuals with moderate renal dysfunction and require their dose to be reduced to $300 \mathrm{mg}$ every 48 hours (rather than daily). These predictions highlight the need for clinical studies for confirmation of dosages in this neglected population. In the absence of dosing guidelines in the elderly population, some patients are likely to be prescribed higher doses than they require, which may cause toxicity. These predictions raise concerns about whether the use of TDF should be 
avoided in elderly patients since renal function testing may not be feasible in communities where affordability is a problem. In addition, significantly higher exposure is expected in individuals older than 75 years, as seen in Fig. 4. Based on the data in Fig. 4, dosage adjustments may be required in these older patients when taking TDF, since the exposure (AUC) ratio is higher when compared with the 65-74 year group, and the GFR is also lower. However, the lifespan of HIV/AIDS patients does not usually exceed 75 years.

Exposure predicted for a standard dose of FTC in the elderly was comparable with that observed in subjects with $\mathrm{CL}_{\mathrm{CR}} \geq 50 \mathrm{~mL} / \mathrm{min}$, where no change in dosage is recommended [10]. Despite the increase in exposure predicted in elderly subjects on a standard dose of 3TC, no dosage adjustment is recommended since it can be compared with exposures observed in subjects with normal renal function [9]. In addition to comparison of the mean predicted AUCs with the mean observed AUCs for FTC and 3TC [23, 28], comparisons of the maximum predicted AUCs with the observed AUCs showed that individuals with high variability from the mean were also not eligible for dosage adjustments. Clinical studies to verify these findings will be beneficial.

Elderly patients on these drugs should be carefully monitored since a few of the patients, particularly those on TDF, may have exposures that are similar to those seen in moderate renal impairment and may require dosage adjustments. Furthermore, elderly patients are likely to be more sensitive to toxicity. On the other hand, the marginal increase in exposure in the elderly may have some therapeutic benefits, as seen by their better virological response [41, 42]. However, patients over 50 years tend to have CD4 cell reconstitution that is significantly slower than in younger patients, which could be partially explained by the advanced disease at diagnosis and senescence. This impaired immunologic response may explain their higher risk of clinical disease progression [41-43].

3TC is generally a well-tolerated drug and studies have reported relatively minor adverse effects such as fatigue, malaise, headache, diarrhoea and sleep disturbances [58]. FTC is practically devoid of any significant side effects [32]. Hyperpigmentation of palms and soles and red cell aplasia have been reported in a few patients [10, 44]. A modest but significant loss of renal function as well as other forms of acute renal toxicity have been associated with the use of TDF [45]. Age and higher TDF plasma concentrations are correlated with a higher risk for renal toxicity [34, 46, 47]. There is no clear threshold to guide the dose adjustment; however, no dosage adjustment was deemed necessary for patients with mild renal impairment [48]. Due to the risk of renal toxicity, the GFR of patients taking TDF should be monitored, and this study suggests that some patients aged over 65 years may carry a higher risk and therefore should be monitored more closely.
The use of a Caucasian Healthy Geriatric model was one of the primary limitations of this modelling exercise. The HIV infection may impact on physiological parameters that can influence the clinical as well as the aging process. The sparsity of data required for the development and verification of models for an HIV-infected young population and an HIV-infected geriatric population for comparison, prevented the use of these more appropriate population models. However, the implemented population models were able to recover the available clinical data adequately. Future studies should also consider the ethnicity of populations used in the modelling. Since the HIV infection is prevalent mainly in African patients (53\% of the 36.9 million people globally living with HIV), the development of an African HIVinfected population is warranted. A further limitation of the study was that the renal impairment studies providing the reference exposures were conducted in a limited number of patients [10, 26, 34]. Although PBPK modelling offers the advantage of simulations of intracellular and tissue concentrations of parent drugs and metabolites, such simulations were not attempted in this study since comparative clinical data was not available for model verification.

Although transporters are involved with the PK of these drugs, the PBPK models did not account for transporter activity changes in the elderly. In the kidney, TDF is mainly transported by OAT1 and MRP4 [49-52]. Lamivudine is a substrate of OCT2, MATE1 and MATE-K [53-55] and FTC is a substrate of MATE1 [56, 57]. Any change in the expression or activity of these transporters could influence the renal clearance of the drugs. However, robust data indicating any change in the expression or activity of transporters in the kidney is not available for the human elderly population [58]. No change in absolute abundance in the liver for BCRP, P-gp, MRP2, OAT2 and OAT7 have been shown for elderly patients [59-63]. Therefore, the transporter activity was assumed to be similar to that in younger subjects. Despite this assumption, the model recovered the PK in the older subjects adequately.

\section{Conclusion}

The PBPK models for TDF, FTC and 3TC recovered the clinical data in older subjects acceptably. Exposure to the three renally excreted drugs increased with age, with mean increases of $48 \%, 42 \%$ and $40 \%$ predicted for TDF, 3TC and FTC, respectively. A comparison of the mean predicted exposure (as assessed by $\mathrm{AUC}_{\infty}$ ) in the elderly with the observed exposure in patients with different levels of renal function indicated that no dosage adjustment is essential in the majority of elderly patients on standard doses of each of the three drugs. However, a small percentage $(22 \%)$ of 
patients on TDF were predicted to show exposures that required dose reductions. Clinical studies to verify these findings are warranted. In addition, elderly subjects on TDF should be carefully monitored.

\section{Compliance with ethical standards}

Funding No financial support was received for this study.

Conflict of interest M. De Sousa Mendes and M. Chetty are employees of Certara UK, Simcyp Division.

Open Access This article is distributed under the terms of the Creative Commons Attribution-NonCommercial 4.0 International License (http://creativecommons.org/licenses/by-nc/4.0/), which permits any noncommercial use, distribution, and reproduction in any medium, provided you give appropriate credit to the original author(s) and the source, provide a link to the Creative Commons license, and indicate if changes were made.

\section{References}

1. Hilmer SN, McLachlan AJ, Le Couteur DG. Clinical pharmacology in the geriatric patient. Fundam Clin Pharmacol. 2007;21(3):217-30.

2. Chetty M, Johnson TN, Polak S, Salem F, Doki K, RostamiHodjegan A. Physiologically based pharmacokinetic modelling to guide drug delivery in older people. Adv Drug Deliv Rev. 2018;135:85-96.

3. Stader F, Siccardi M, Battegay M, Kinvig H, Penny MA, Marzolini C. Repository describing an aging population to inform physiologically based pharmacokinetic models considering anatomical, physiological, and biological age-dependent changes. Clin Pharmacokinet. 2019;58(4):483-501.

4. Schlender J-F, Meyer M, Thelen K, Krauss M, Willmann S, Eissing T, Jaehde U. Development of a whole-body physiologically based pharmacokinetic approach to assess the pharmacokinetics of drugs in elderly individuals. Clin Pharmacokinet. 2016;55(12):1573-89.

5. Davies DF, Shock NW. Age changes in glomerular filtration rate, effective renal plasma flow, and tubular excretory capacity in adult males. J Clin Investig. 1950;29(5):496-507.

6. McDONALD RK, Solomon DH, Shock NW. Aging as a factor in the renal hemodynamic changes induced by a standardized pyrogen. J Clin Investig. 1951;30(5):457-62.

7. Slack TK, Wilson DM. Normal renal function: CIN and CPAH in healthy donors before and after nephrectomy. Mayo Clin Proc. 1976;51(5):296-300.

8. Gilead Sciences, Inc. Product information: VIREAD(R) oral tablets, tenofovir disoproxil fumarate oral tablets. 2010. https ://www.viread.com/global_pdf/Viread_FPI.pdf.

9. GlaxoSmithKline. Research Triangle Park. Product Information: Epivir(R), lamivudine. 2002. https://www.accessdata.fda.gov/ drugsatfda.docs/label/2017/021500s028,021896s025lbl.pdf.

10. Gilead Sciences, Inc. Product Information: Emtriva(TM), emtricitabine capsules. 2003. https://www.accessdata.fda.gov/ drugsatfda.docs/label/2013/021003s015,021004s015lbl.pdf.

11. NHANES - National Health and Nutrition Examination Survey Homepage [Internet]. 2019. https://www.cdc.gov/nchs/nhanes/ index.htm. Accessed 17 June 2019.
12. Bahat G, Tufan F, Akin S, Akpinar TS, Tufan A, Ozturk S, Saka B, Sanli Y, Tugrul G, Adalet I, Oner B, Erten N, Karan MA. Which method is better in the elderly to estimate glomerular filtration rate? Eur Geriatr Med. 2012;1(3):S106.

13. Emoto C, Johnson TN, McPhail BT, Vinks AA, Fukuda T. Using a vancomycin PBPK model in special populations to elucidate case-based clinical PK observations. CPT Pharmacomet Syst Pharmacol. 2018;7(4):237-50.

14. De Sousa Mendes M, Hirt D, Urien S, Valade E, Bouazza N, Foissac F, Blanche S, Treluyer J-M, Benaboud S. Physiologically-based pharmacokinetic modeling of renally excreted antiretroviral drugs in pregnant women. Br J Clin Pharmacol. 2015;80(5):1031-41.

15. Wagner C, Pan Y, Hsu V, Grillo JA, Zhang L, Reynolds KS, Sinha V, Zhao P. Predicting the effect of cytochrome P450 inhibitors on substrate drugs: analysis of physiologically based pharmacokinetic modeling submissions to the US Food and Drug Administration. Clin Pharmacokinet. 2015;54(1):117-27.

16. Shaw JP, Sueoko CM, Oliyai R, Lee WA, Arimilli MN, Kim CU, Cundy KC. Metabolism and pharmacokinetics of novel oral prodrugs of 9-[(R)-2-(phosphonomethoxy)propyl]adenine (PMPA) in dogs. Pharm Res. 1997;14(12):1824-9.

17. Deeks SG, Barditch-Crovo P, Lietman PS, Hwang F, Cundy KC, Rooney JF, Hellmann NS, Safrin S, Kahn JO. Safety, pharmacokinetics, and antiretroviral activity of intravenous 9-[2-(R)(phosphonomethoxy)propyl]adenine, a Novel anti-human immunodeficiency virus (HIV) therapy, in HIV-infected adults. Antimicrob Agents Chemother. 1998;42(9):2380.

18. Duwal S, Schütte C, von Kleist M. Pharmacokinetics and pharmacodynamics of the reverse transcriptase inhibitor tenofovir and prophylactic efficacy against HIV-1 infection. Tang J, editor. PLoS One. 2012;7(7):e40382.

19. Rodgers T, Rowland M. Physiologically based pharmacokinetic modelling 2: predicting the tissue distribution of acids, very weak bases, neutrals and zwitterions. J Pharm Sci. 2006;95(6):1238-57.

20. Mathias AA, Hinkle J, Menning M, Hui J, Kaul S, Kearney BP, Efavirenz/Emtricitabine/Tenofovir Disoproxil Fumarate SingleTablet Regimen Development Team. Bioequivalence of efavirenz/ emtricitabine/tenofovir disoproxil fumarate single-tablet regimen. J Acquir Immune Defic Syndr 1999. 2007;46(2):167-73.

21. Blum MR, Chittick GE, Begley JA, Zong J. Steady-state pharmacokinetics of emtricitabine and tenofovir disoproxil fumarate administered alone and in combination in healthy volunteers. J Clin Pharmacol. 2007;47(6):751-9.

22. Wenning LA, Friedman EJ, Kost JT, Breidinger SA, Stek JE, Lasseter KC, Gottesdiener KM, Chen J, Teppler H, Wagner JA, Stone JA, Iwamoto M. Lack of a significant drug interaction between raltegravir and tenofovir. Antimicrob Agents Chemother. 2008;52(9):3253-8.

23. Dumond JB, Adams JL, Prince HMA, Kendrick RL, Wang R, Jennings SH, Malone S, White N, Sykes C, Corbett AH, Patterson KB, Forrest A, Kashuba ADM. Pharmacokinetics of two common antiretroviral regimens in older HIV-infected patients: a pilot study. HIV Med. 2013;14(7):401-9.

24. Benaboud S, Treluyer JM, Urien S, Blanche S, Bouazza N, Chappuy H, Rey E, Pannier E, Firtion G, Launay O, Hirt D. Pregnancy-related effects on lamivudine pharmacokinetics in a population study with 228 women. Antimicrob Agents Chemother. 2012;56(2):776-82.

25. ViiV Healthcare Shire Canada. monographie Heptovir,lamivudine [Internet]. 2011. http://www.gsk.ca/french/docs-pdf/productmonographs/Heptovir.pdf. Accessed 21 Jan 2014.

26. Heald AE, Hsyu PH, Yuen GJ, Robinson P, Mydlow P, Bartlett JA. Pharmacokinetics of lamivudine in human immunodeficiency 
virus-infected patients with renal dysfunction. Antimicrob Agents Chemother. 1996;40(6):1514-9.

27. Yuen GJ, Lou Y, Bumgarner NF, Bishop JP, Smith GA, Otto VR, Hoelscher DD. Equivalent steady-state pharmacokinetics of lamivudine in plasma and lamivudine triphosphate within cells following administration of lamivudine at 300 milligrams once daily and 150 milligrams twice daily. Antimicrob Agents Chemother. 2004;48(1):176-82.

28. Shibata H, Yoshihiko H, Masao S, Yukie S, Kunihisa M, Junko N. Comparison of pharmacokinetics of lamivudine between elderly volunteers and healthy young male volunteers. Clin Ther Med. 1997;12:5451-4.

29. Tatsunami S, Ito A, Kawata K, Kuwabara R, Fukutake K, Yamada $\mathrm{K}$. Pharmacokinetic consideration on administration regimen of lamivudine in japanese patients infected with HIV-1. Int J Clin Pharmacol Ther. 2000;38(7):333-8.

30. Hirt D, Urien S, Rey E, Arrive E, Ekouevi DK, Coffie P, Leang SK, Lalsab S, Avit D, Nerrienet E, McIntyre J, Blanche S, Dabis F, Treluyer J-M. Population pharmacokinetics of emtricitabine in human immunodeficiency virus type 1-infected pregnant women and their neonates. Antimicrob Agents Chemother. 2008;53(3):1067-73.

31. Gish RG, Leung NWY, Wright TL, Trinh H, Lang W, Kessler HA, Fang L, Wang LH, Delehanty J, Rigney A, Mondou E, Snow A, Rousseau F. Dose range study of pharmacokinetics, safety, and preliminary antiviral activity of emtricitabine in adults with hepatitis B virus infection. Antimicrob Agents Chemother. 2002;46(6):1734-40.

32. Wang LH, Begley J, St Claire RL III, Harris J, Wakeford C, Rousseau FS. Pharmacokinetic and pharmacodynamic characteristics of emtricitabine support its once daily dosing for the treatment of HIV infection. AIDS Res Hum Retrovir. 2004;20(11):1173-82.

33. Zong J, Chittick GE, Wang LH, Hui J, Begley JA, Blum MR. Pharmacokinetic evaluation of emtricitabine in combination with other nucleoside antivirals in healthy volunteers. J Clin Pharmacol. 2007;47(7):877-89.

34. Kearney BP, Flaherty JF, Shah J. Tenofovir disoproxil fumarate. Clin Pharmacokinet. 2004;43(9):595-612.

35. Polasek TM, Patel F, Jensen BP, Sorich MJ, Wiese MD, Doogue MP. Predicted metabolic drug clearance with increasing adult age. Br J Clin Pharmacol. 2013;75(4):1019-28.

36. Rhee S-J, Chung H, Yi S, Yu K-S, Chung J-Y. Physiologically based pharmacokinetic modelling and prediction of metformin pharmacokinetics in renal/hepatic-impaired young adults and elderly populations. Eur J Drug Metab Pharmacokinet. 2017;42(6):973-80.

37. Valade E, Tréluyer J-M, Bouazza N, Ghosn J, Foissac F, Benaboud S, Fauchet F, Viard J-P, Urien S, Hirt D. Population pharmacokinetics of emtricitabine in HIV-1-infected adult patients. Antimicrob Agents Chemother. 2014;58(4):2256-61.

38. Moore KH, Yuen GJ, Hussey EK, Pakes GE, Eron JJ Jr, Bartlett JA. Population pharmacokinetics of lamivudine in adult human immunodeficiency virus-infected patients enrolled in two phase III clinical trials. Antimicrob Agents Chemother. 1999;43(12):3025-9.

39. Panhard X, Legrand M, Taburet A-M, Diquet B, Goujard C, Mentré F, The Cophar 1-ANRS 102 Study Group. Population pharmacokinetic analysisof lamivudine, stavudine and zidovudine in controlled HIV-infected patients on HAART. Eur J Clin Pharmacol. 2007;63(11):1019-29.

40. Bouazza N, Tréluyer J-M, Ghosn J, Hirt D, Benaboud S, Foissac F, Viard J-P, Urien S. Evaluation of effect of impaired renal function on lamivudine pharmacokinetics. Br J Clin Pharmacol. 2014;78(4):847-54.

41. Grabar S, Kousignian I, Sobel A, Le Bras P, Gasnault J, Enel $\mathrm{P}$, Jung C, Mahamat A, Lang J-M, Costagliola D. Immunologic and clinical responses to highly active antiretroviral therapy over 50 years of age. Results from the French Hospital Database on HIV. AIDS Lond Engl. 2004;18(15):2029-38.

42. Collaboration of Observational HIV Epidemiological Research Europe (COHERE) Study Group, Sabin CA, Smith CJ, d'Arminio Monforte A, Battegay M, Gabiano C, Galli L, Geelen S, Gibb D, Guiguet M, Judd A, Leport C, Dabis F, Pantazis N, Porter K, Raffi F, Thorne C, Torti C, Walker S, Warszawski J, Wintergerst U, Chene G, Lundgren J. Response to combination antiretroviral therapy: variation by age. AIDS Lond Engl. 2008;22(12):1463-73.

43. Mussini C, Manzardo C, Johnson M, Monforte ADA, Ubertifoppa C, Antinori A, Gill MJ, Sighinolfi L, Borghi V, Lazzarin A, Miró JM, Sabin C. Patients presenting with Aids in the Haart era: a collaborative cohort analysis. AIDS. 2008;22(18):2461-9.

44. Cohen K, Viljoen C, Njuguna C, Maartens G. Emtricitabine-associated red cell aplasia. AIDS Lond Engl. 2019;33(6):1095-6.

45. Cooper RD, Wiebe N, Smith N, Keiser P, Naicker S, Tonelli M. Systematic review and meta-analysis: renal safety of tenofovir disoproxil fumarate in HIV-infected patients. Clin Infect Dis Off Publ Infect Dis Soc Am. 2010;51(5):496-505.

46. Rodríguez-Nóvoa S, Labarga P, D'Avolio A, Barreiro P, Albalate M, Vispo E, Solera C, Siccardi M, Bonora S, Di Perri $\mathrm{G}$, Soriano V. Impairment in kidney tubular function in patients receiving tenofovir is associated with higher tenofovir plasma concentrations. AIDS. 2010;24(7):1064.

47. Hall AM, Hendry BM, Nitsch D, Connolly JO. Tenofovirassociated kidney toxicity in HIV-infected patients: a review of the evidence. Am J Kidney Dis Off J Natl Kidney Found. 2011;57(5):773-80.

48. Barditch-Crovo P, Deeks SG, Collier A, Safrin S, Coakley DF, Miller M, Kearney BP, Coleman RL, Lamy PD, Kahn JO, McGowan I, Lietman PS. Phase I/II trial of the pharmacokinetics, safety, and antiretroviral activity of tenofovir disoproxil fumarate in human immunodeficiency virus-infected adults. Antimicrob Agents Chemother. 2001;45(10):2733-9.

49. Mathialagan S, Piotrowski MA, Tess DA, Feng B, Litchfield J, Varma MV. Quantitative prediction of human renal clearance and drug-drug interactions of organic anion transporter substrates using in vitro transport data: a relative activity factor approach. Drug Metab Dispos Biol Fate Chem. 2017;45(4):409-17.

50. Cihlar T, LaFlamme G, Fisher R, Carey AC, Vela JE, Mackman R, Ray AS. Novel nucleotide human immunodeficiency virus reverse transcriptase inhibitor GS-9148 with a low nephrotoxic potential: characterization of renal transport and accumulation. Antimicrob Agents Chemother. 2008;53(1):150-6.

51. Ray AS, Cihlar T, Robinson KL, Tong L, Vela JE, Fuller MD, Wieman LM, Eisenberg EJ, Rhodes GR. Mechanism of active renal tubular efflux of tenofovir. Antimicrob Agents Chemother. 2006;50(10):3297-304.

52. Cihlar T, Ray AS, Laflamme G, Vela JE, Tong L, Fuller MD, Roy A, Rhodes GR. Molecular assessment of the potential for renal drug interactions between tenofovir and HIV protease inhibitors. Antivir Ther. 2007;12(2):267-72.

53. Minuesa G, Volk C, Molina-Arcas M, Gorboulev V, Erkizia I, Arndt P, Clotet B, Pastor-Anglada M, Koepsell H, MartinezPicado J. Transport of lamivudine [(-)-L-2',3'-dideoxy-3'thiacytidine] and High-affinity interaction of nucleoside reverse transcriptase inhibitors with human organic cation transporters 1, 2, and 3. J Pharmacol Exp Ther. 2009;329(1):252-61.

54. Jung N, Lehmann C, Rubbert A, Knispel M, Hartmann P, van Lunzen J, Stellbrink H-J, Faetkenheuer G, Taubert D. Relevance of the organic cation transporters 1 and 2 for antiretroviral 
drug therapy in human immunodeficiency virus infection. Drug Metab Dispos. 2008;36(8):1616-23.

55. Müller F, König J, Hoier E, Mandery K, Fromm MF. Role of organic cation transporter OCT2 and multidrug and toxin extrusion proteins MATE1 and MATE2-K for transport and drug interactions of the antiviral lamivudine. Biochem Pharmacol. 2013;86(6):808-15.

56. Bousquet L, Pruvost A, Didier N, Farinotti R, Mabondzo A. Emtricitabine: Inhibitor and substrate of multidrug resistance associated protein. Eur J Pharm Sci. 2008;35(4):247-56.

57. Reznicek J, Ceckova M, Cerveny L, Müller F, Staud F. Emtricitabine is a substrate of MATE1 but not of OCT1, OCT2, P-gp, BCRP or MRP2 transporters. Xenobiotica Fate Foreign Compd Biol Syst. 2017;47(1):77-85.

58. Morrissey KM, Stocker SL, Wittwer MB, Xu L, Giacomini KM. Renal transporters in drug development. Annu Rev Pharmacol Toxicol. 2013;53:503-29.

59. Prasad B, Lai Y, Lin Y, Unadkat JD. Interindividual variability in the hepatic expression of the human breast cancer resistance protein (BCRP/ABCG2): effect of age, sex, and genotype. J Pharm Sci. 2013;102(3):787-93.

60. Prasad B, Evers R, Gupta A, Hop CECA, Salphati L, Shukla $\mathrm{S}$, Ambudkar SV, Unadkat JD. Interindividual variability in hepatic organic anion-transporting polypeptides and P-glycoprotein $(\mathrm{ABCB} 1)$ protein expression: quantification by liquid chromatography tandem mass spectroscopy and influence of genotype, age, and sex. Drug Metab Dispos Biol Fate Chem. 2014;42(1):78-88.
61. Deo AK, Prasad B, Balogh L, Lai Y, Unadkat JD. Interindividual variability in hepatic expression of the multidrug resistanceassociated protein 2 (MRP2/ABCC2): quantification by liquid chromatography/tandem mass spectrometry. Drug Metab Dispos Biol Fate Chem. 2012;40(5):852-5.

62. Li N, Zhang Y, Hua F, Lai Y. Absolute difference of hepatobiliary transporter multidrug resistance-associated protein (MRP2/Mrp2) in liver tissues and isolated hepatocytes from rat, dog, monkey, and human. Drug Metab Dispos Biol Fate Chem. 2009;37(1):66-73.

63. Vildhede A, Kimoto E, Rodrigues AD, Varma MVS. Quantification of hepatic organic anion transport proteins OAT2 and OAT7 in human liver tissue and primary hepatocytes. Mol Pharm. 2018;15(8):3227-35.

64. Janneh $\mathrm{O}$, Khoo S. Interactions of tenofovir, lamivudine, abacavir and didanosine in primary human cells. Pharmaceutics. 2011;3(4):326-37.

65. Lee WA, He G-X, Eisenberg E, Cihlar T, Swaminathan S, Mulato A, Cundy KC. Selective intracellular activation of a novel prodrug of the human immunodeficiency virus reverse transcriptase inhibitor tenofovir leads to preferential distribution and accumulation in lymphatic tissue. Antimicrob Agents Chemother. 2005;49(5):1898-906.

66. Johnson MA, Moore KH, Yuen GJ, Bye A, Pakes GE. Clinical pharmacokinetics of lamivudine. Clin Pharmacokinet. 1999;36(1):41-66. 